\title{
THE RECOGNITION OF PRIMARY TUBERCULOUS INFECTION OF THE MOUTH
}

\author{
BY \\ J. BOYES, J. D. T. JONES and F. J. W. MILLER \\ From the Sutherland Dental School, Departments of Surgery and Child Health, University of Durham
}

(RECEIVED FOR PUBLICATHON DECEMBER 29, 1955)

Primary tuberculous infection of the mouth is uncommon. One of us (Miller, 1953), in a series of 28 cases of primary infection of the skin or mucosae, described three cases which had previously been discussed at a meeting of the Royal Society of Medicine (Boyes, 1950). At that time only two other examples had been recorded in Britain (Cameron, 1939; Brand and Ballard, 1951). Since then one further case, of bovine infection, has been reported (Galloway and Horne, 1953). There are, however, references in the Continental literature, and Duken (1933) reported 10 cases in which tuberculous ulcers were found on gum or tonsils. Yet tuberculous submandibular adenitis is not uncommon, and the glands in the cases described, except that they were all of recent origin, had no special characteristics. On these grounds we thought that failure to find the primary focus in cases of recent tuberculous submandibular lymphadenitis might be due to lack of diligence in search or skill in recognition. During a study of the pathogenesis of tuberculous lymphadenitis we have taken, therefore, particular care in examining the mouth whenever we have seen a case of tuberculous submandibular adenitis of 'recent' origin, i.e., one with a short history of six months and without calcium deposit, for it is only in cases of recent origin that one can reasonably expect to find a primary focus. In the absence of any evidence of earlier tuberculosis in the body, we have taken the presence of a tuberculous lesion in the mouth and tuberculous regional adenitis to indicate a primary tuberculous complex, for in clinical work we are usually denied the opportunity of observing tuberculin conversion, and therefore final proof that the infection is occurring in a nonsensitized person.

Since the first three cases were reported we have seen six others. We wish, however, to record here only seven of the nine cases, as the eighth was in a man of 58 years and merits separate description and discussion as a reinfection primary complex, and the ninth, a woman of 22 years, although we feel sure of the nature of the infection, has as yet no calcification or softening in the cervical glands. The seven cases illustrate the difficulty of recognition, the transient nature of the primary focus, and, in this series, the association of tuberculous infection with dental trauma and acute nontuberculous alveolar abscess.

The clinical details are given in Table 1. The detailed histories are presented in the order in which the cases were seen; the tuberculous nature of the focus and the glands has been proven in every case. The ages of the patients were from 2 to 17 years; all except two (Cases 1 and 4) had a history of trauma, and these two were strikingly similar in clinical appearance (Figs. 1 and 6). Four of the other five had had teeth extracted, three following alveolar abscesses. In no case was there known contact with a tuberculous adult, and the precise sources of the infecting organisms were not discovered.

\section{Clinical Histories}

Case 1. A bright, intelligent girl almost 8 years old, the younger daughter in a lower middle class family, was first seen in October, 1948, when she was brought to hospital with a painless swelling on the ramus of the mandible on the left side. Both the girl and her parents were also aware that she had a painless ulcer on the left upper gum. Both swelling and ulcer had been present for at least three weeks. The girl had not had any other symptoms and appeared in good health. On examination, the facts were confirmed. The ulcer had destroyed the mucous membrane above the left lateral and canine incisors, the base being uneven granulation tissue and its upper limit undermining the gingivo-labial sulcus (Fig. 1). The facial gland was painless and firm, and the tonsillar gland was also enlarged. No other glandular enlargement and no other evidence of tuberculosis or other disease was present. Her tuberculin reaction (1:1,000 O.T.) was strongly positive; radiographs of the chest and neck did not reveal any evidence of active disease or calcification. Biopsy of the ulcer showed tuberculous granulation tissue. Streptomycin $(0.5 \mathrm{~g}$. daily) was 
TABLE

DETAILS OF SEVEN CASES OF PRIMARY TUBERCULOSIS OF THE MOUTH IN 1948-53

\begin{tabular}{|c|c|c|c|c|c|c|c|c|c|c|}
\hline $\begin{array}{l}\text { Case } \\
\text { No. }\end{array}$ & $\begin{array}{l}\text { Age } \\
\text { First } \\
\text { Seen }\end{array}$ & $\begin{array}{c}\text { Duration } \\
\text { of } \\
\text { Obser- } \\
\text { vation } \\
\text { (years) }\end{array}$ & $\begin{array}{c}\text { Probable } \\
\text { Duration } \\
\text { of } \\
\text { Infection } \\
\text { when Seen }\end{array}$ & $\begin{array}{l}\text { Site of } \\
\text { Primary } \\
\text { Focus }\end{array}$ & $\begin{array}{c}\text { Condition of } \\
\text { Glands when } \\
\text { First Seen }\end{array}$ & Trauma & $\begin{array}{l}\text { Operative } \\
\text { Treatment } \\
\text { of Glands }\end{array}$ & $\begin{array}{l}\text { Further } \\
\text { Abscesses }\end{array}$ & $\begin{array}{l}\text { Scars } \\
\text { Visible (of } \\
\text { Primary) }\end{array}$ & $\begin{array}{l}\text { Ca } \\
\text { in } \\
\text { Gland }\end{array}$ \\
\hline $\begin{array}{l}1 \\
2\end{array}$ & $\begin{array}{l}71 \frac{1}{2} \\
8 \frac{1}{12}\end{array}$ & $7^{\frac{1}{2}}$ & $\begin{array}{l}3 \text { wk. } \\
4 \text { wk. }\end{array}$ & $\begin{array}{l}\text { L. alveolus } \\
\text { Tooth socket }\end{array}$ & $\begin{array}{l}\text { Hard } \\
\text { Hard }\end{array}$ & $\begin{array}{l}\text { None } \\
\text { Extractions }\end{array}$ & $\begin{array}{l}\text { Incision } \\
\text { Incision }\end{array}$ & $\begin{array}{l}\text { Yes } \\
\text { Yes }\end{array}$ & $\begin{array}{l}\text { Yes } \\
\text { No }\end{array}$ & + \\
\hline 3 & $2 i^{2}$ & 7 & 8 wk. & $\begin{array}{c}\text { Alveolar } \\
\text { buccal }\end{array}$ & Softening & $\begin{array}{l}\text { Stones in } \\
\text { mouth }\end{array}$ & Incision & Yes & No & + \\
\hline 4 & 17 & 3 & $3 \mathrm{mth}$. & L. alveolus & Hard & None & $\begin{array}{l}\text { Dissection } \\
\text { (human }\end{array}$ & No & Yes & + \\
\hline 5 & 10 & 3 & $4 \mathrm{mth}$. & Tooth socket & Hard & $\begin{array}{l}\text { Tooth } \\
\text { extraction, } \\
\text { alveolar }\end{array}$ & $\begin{array}{c}\text { organisms) } \\
\text { Dissection }\end{array}$ & No & No & + \\
\hline 6 & 6 & $2 \frac{7}{12}$ & 8 wk. & $\begin{array}{c}\text { Alveolar } \\
\text { mucosa }\end{array}$ & $\begin{array}{l}\text { Soft and } \\
\text { ulcerated }\end{array}$ & $\begin{array}{l}\text { abscess } \\
\text { Tooth } \\
\text { extraction, } \\
\text { alveolar }\end{array}$ & Incision & Yes & No & $\begin{array}{l}\text { Not } \\
\text { yet }\end{array}$ \\
\hline 7 & $8_{1: 2}^{: 5}$ & 2,2 & 10 wk. & $\begin{array}{l}\text { Alveolus over } \\
\text { tooth socket }\end{array}$ & Softened & $\begin{array}{l}\text { abscess } \\
\text { Tooth } \\
\text { extraction, } \\
\text { alveolar } \\
\text { abscess }\end{array}$ & Incision & No & Yes & $\begin{array}{l}\text { Not } \\
\text { yet }\end{array}$ \\
\hline
\end{tabular}

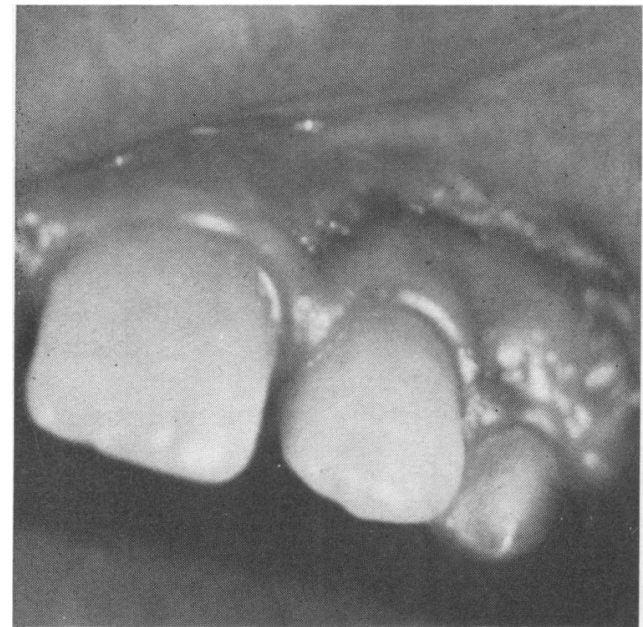

FIG. 1.-Case 1. Ulcer on left alveolus extending backwards from the left lateral incisor and eroding the mucosa.

given for three weeks; during this time the ulcer healed considerably, and the glands became smaller and more discrete. She thereafter continued to attend hospital as an out-patient. The ulcer continued to heal, but it is almost impossible to say when healing was complete, as it never gave cause for complaint or anxiety. A visible scar has remained (Fig. 2). Almost a year after the streptomycin was stopped, the facial gland enlarged and softened. It was incised and subsequently discharged caseous material. Three months later, a second abscess developed in the submandibular gland and healed slowly after incision. The tonsillar gland, which was palpable, has never softened; radiological calcification is now visible.

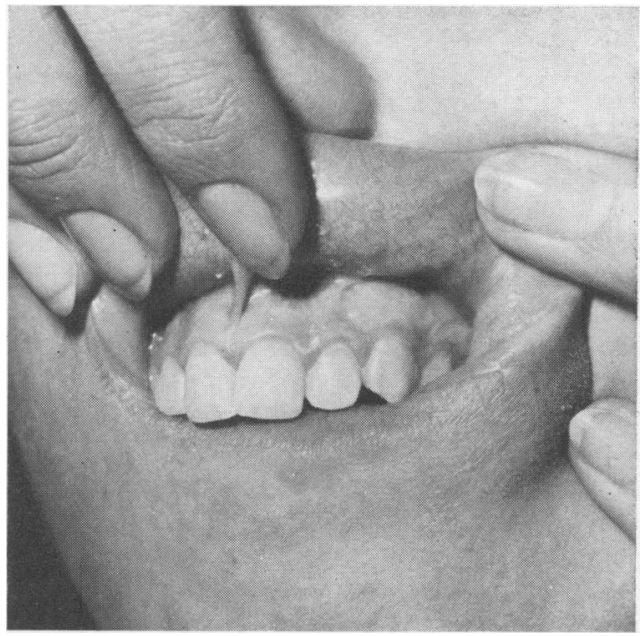

FIG. 2.-Case 1. The scar of the primary focus and the area of destroyed mucosa.

Case 2. Aged 8, the son of artisan parents, this boy was referred to hospital with a large, painless submandibular swelling, which had appeared two weeks after tooth extraction and had been present for three weeks altogether.

On examination the mouth showed a painless circular ulcer with rather raised edges in one of the tooth sockets (Fig. 3). The boy admitted he knew about it but had not complained because it was painless. The tuberculin test $(1: 1,000$ O.T.) was strongly positive. No evidence of tuberculosis was found elsewhere. Biopsy of the edges of the ulcer showed tissue characteristic of tuberculosis. Six weeks after their first appearance the glands softened and the overlying skin became red; aspirated 


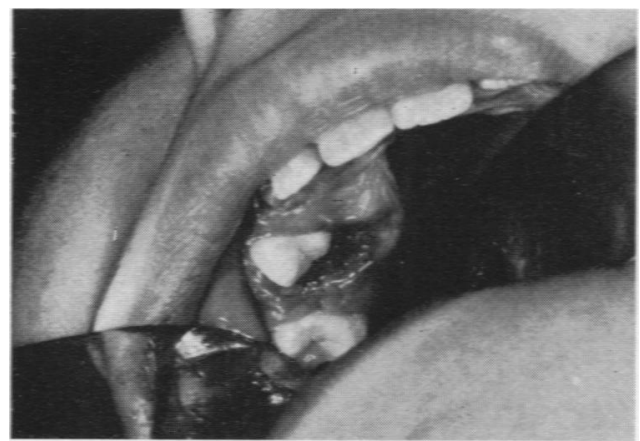

Fig. 3. - Case 2. Circular uker at site of tooth extraction.

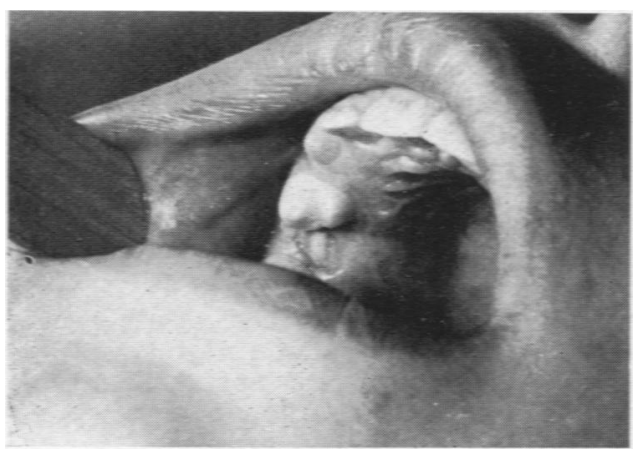

FiG. 4.-Case 2. Three months after Fig. 3, showing permanent tooth erupting at site of primary infection.

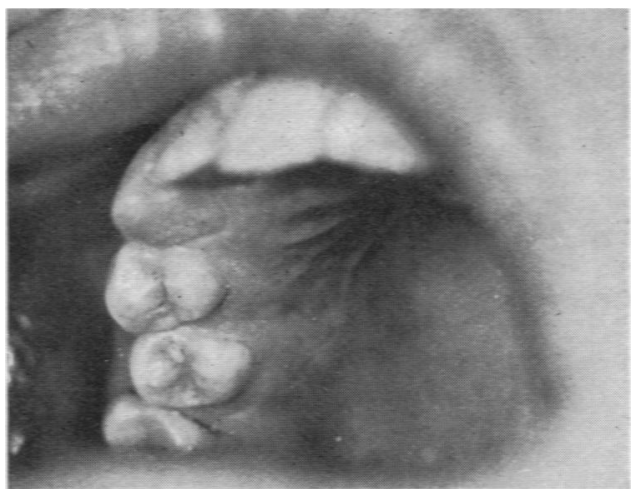

Fig. 5.-Case 2. Eighteen months after infection the site of primary infection has been obliterated by the permanent tooth.

pus contained tubercle bacilli. Streptomycin $(0.5 \mathrm{~g}$. daily) was given, but only for 12 days as there was a severe reaction at the site of injection. During this time the primary focus healed rapidly but the gland abscess became larger. Three months after the boy's first visit, the primary focus was soundly healed and appeared only as a shallow circle, 1 in. in diameter through which a permanent tooth was erupting (Fig. 4).
Within 18 months all traces of the primary lesion had vanished (Fig. 5). In January, 1950, nine months after infection, the submandibular glands softened again and were removed by dissection. The wound healed by first intention; no further abscesses have appeared, but on radiological examination calcification is present.

Case 3. Aged 2, a healthy girl, the only child of young capable parents, was admitted to hospital with a softening left submandibular lymphadenitis of eight weeks' duration. An adjacent gland was also enlarged but not soft. Two weeks before the gland was first noticed, the mother had found the child with some small sharp stones from the roadside in her mouth, but as far as she could then see there was no injury. There had not been any other trauma or known contact with tuberculosis. The only other abnormal finding was an ulcer in the buccal sulcus about 1 in. long, difficult to see unless the cheek and gum were well separated, deep and sharp in outline. Biopsy showed it to be tuberculous. Pus containing tubercle bacilli was aspirated from the gland, and the abscess later incised. Unfortunately, the position of the primary focus, far posterior in the buccal sulcus, made it difficult to photograph. Streptomycin was given $(0.5 \mathrm{~g}$. daily) for three weeks. The effect was striking: the incision in the submandibular gland healed by first intention; the other gland became smaller, whilst the lesion in the mouth rapidly and almost completely healed. But six weeks later the second gland softened and was incised after another month of streptomycin treatment. In August, 1951, two years after the first admission, a third abscess developed. This also was incised and curetted, and there has not been any further trouble.

Case 4. Aged 17, the second of three children of artisan parents worked as a shop assistant. In January, 1953, she noticed a small lump in the left submandibular region; it was said to be slightly tender but otherwise not troublesome and she felt quite well. After three days she went to her doctor who diagnosed an abscess and gave her a penicillin injection, but the lump did not alter. She was eventually sent to hospital, but the day before going she found, quite accidentally, by pushing her tongue against it, that her gum was uneven. When first seen in March, 1953, she was a healthy looking girl with an obvious left submandibular swelling, which was composed of two enlarged glands; there was also a small gland in front and another behind the sternomastoid. They were not painful or fluctuant and the overlying skin was not adherent. In the mouth, extending from the gum over the left upper premolar and molars, was an ulcer very similar to that seen in Case 1 (Fig. 6). There was no dental caries, no history of trauma, and no known contact with tuberculosis. Her tonsils were normal and the tonsillar glands were not palpable. Streptomycin was started ( $1 \mathrm{~g}$. daily) in the first week in April. Within a week the gland mass was smaller, the glands were discrete, but the uker had not changad. For the next three weeks the glands continued to get smaller, and by now the uker was healing. The strepto- 
mycin was given daily for a month. By May 20, two weeks after the streptomycin had been stopped, the primary lesion looked almost healed and the glands were at their minimum. On June 10, 1953, she was admitted to hospital and the firm glands removed by local dissection with streptomycin cover. The wound healed by

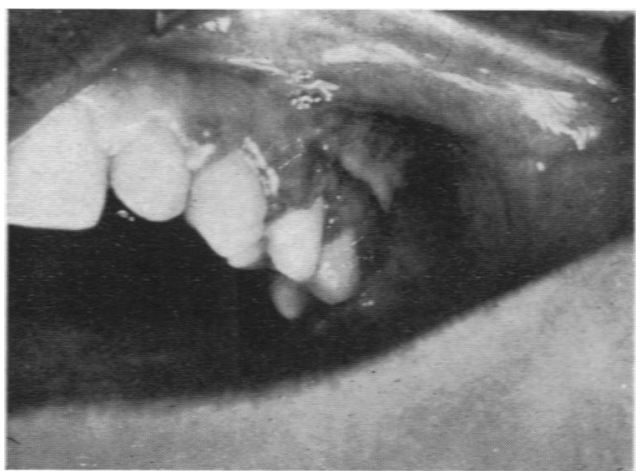

Fig. 6.-Case 4. Uker with irregular edges and granulating base over upper gum extending back from left premolar (March, 1953).

first intention. When seen one year later, there had been no further trouble or complaint, the scar in the neck was firmly healed, no glands were palpable, but radiological calcification was present near the site of operation, and a scar (Fig. 7) has remained on the gum at the site of the primary focus, very similar to that seen in Fig. 2.

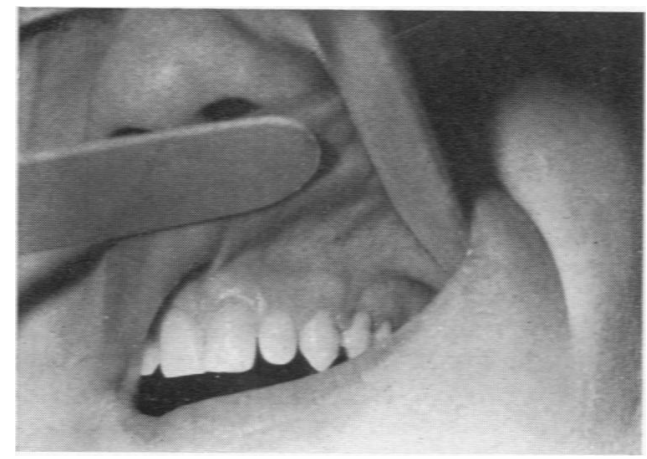

FIG. 7.-Case 4. Scar remaining at site of primary infection.

Case 5. A sturdy boy aged 10, from a miner's family, five months before attendance at hospital suddenly developed a tender swelling of the left cheek, and after three days was taken to a dental clinic where an alveolar abscess was incised. A few days later four teeth were extracted, and three weeks afterwards another swelling, this time painless and firm, appeared in the submandibular region. At this time another child was very ill with pink disease, and as the boy's lump was painless and he seemed well, six weeks elapsed before he was taken again to the dentist, where he was examined and radiographs taken. But the swelling slowly grew larger, and the family doctor sent the child to hospital when the swelling had been present for about 15 weeks.

On examination he had a firm, painless mass in the left submandibular region. Over the outer aspects of the tooth sockets in the left upper jaw there was a small, quite inconspicuous area which looked like an unhealed area of granulation tissue, but no definite ulcer. The tuberculin test was positive. Radiological examination did not reveal any evidence of tuberculosis in the chest or calcification in neck or abdomen. At first there was some discussion whether biopsy of the small area would be profitable, but when it was done examination of the specimen revealed the histological picture of tuberculous infection. The boy was then given streptomycin for six weeks, with considerable reduction in the size of the gland mass and complete healing of the granulating area. For the next two months he was well but the gland remained unchanged, so almost a year after the alveolar abscess the glands were removed by dissection and found to be caseous. The wound healed by first intention, and two years later there has not been any further trouble.

Case 6. Aged 6, the second and younger child of a miner, living in a large colliery village in Northumberland. was admitted to hospital on September 7, 1953, suffering from tuberculous meningitis of about one week's duration. On June 30, eight weeks before the onset of tuberculous meningitis, she had toothache and an alveolar abscess. One week later the tooth was removed and the swelling of the face disappeared. There had also been a tender, firm, submandibular lymphadenitis, but this, though losing its tenderness, did not disappear. After another week, the mother consulted her doctor who said that the swelling was in a gland and that an abscess might ensue. In another few days the family went for a fortnight's holiday, but the child was 'off colour' and the swelling slowly became larger. On return from holiday, the doctor was again consulted, and this time an ulcer was found at the site of the tooth extraction in the sulcus beneath. On August 8 and 9, the submandibular swelling was poulticed and the next day was incised. It did not heal, the skin around the incision became eroded, and on August 21 tubercle bacilli were recovered from the pus. For another 10 days the child seemed well, but early in the morning of September 1, she woke and vomited; the next day she vomited again, was unhappy, refusing her food. She continued in this way for five days, becoming thinner and developing headache, and she was sent to hospital with the clinical diagnosis of early tuberculous meningitis.

On examination she was thin, rather quiet and anxious, but fairly alert and quite responsive: some neck and back stiffness was detected. In the submandibular area on the left side there was an ulcer with a sloughing base and thin undermined edges; adjacent lymph nodes were hard and discrete; the spleen was palpable 1 in. below the costal margin, but no other abnormal signs were found. The tuberculin test (1: 1,000 solution of O.T.) was positive, and the spinal fluid contained 300 lymphocytes and an excess of protein (160 mg. ${ }^{\circ}$ ). In the sulcus 
between the cheek and the alveolar margin at the site of the extraction, was a painless uker 1 in. long, with irregular sharp edges and a yellow base, seen only when the cheek was held away from the gum (Fig. 8), the inner margin of the ulcer extending on to the alveolar margin at the site of the tooth. In the surrounding mucous

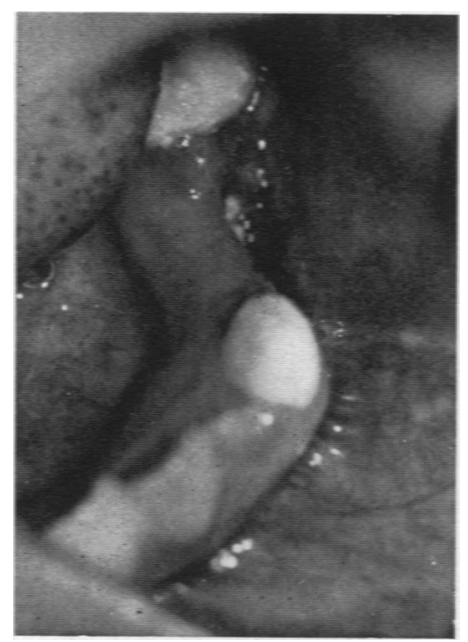

FKG. 8.-Case 6. Lesion in mouth, uber in gingivo-labial sukcus. Two small yellow ukcers are visible on the extreme right of the picture.

membrane, several small yellow-grey nodules, about $1 \mathrm{~mm}$. in diameter, were scattered irregularly. These seem comparable to the satellite nodules sometimes seen in natural primary infection of skin, or in B.C.G. inoculation, and described in the mouth by Horne (1953) in his case report. Fortunately, the child made a straightforward recovery from the meningitis, and at the same time the lesions in the mouth and gland healed. On treatment with streptomycin and P.A.S., within two weeks the mouth uker was smaller, the sloughing yellow base was clean, and progress continued until healing

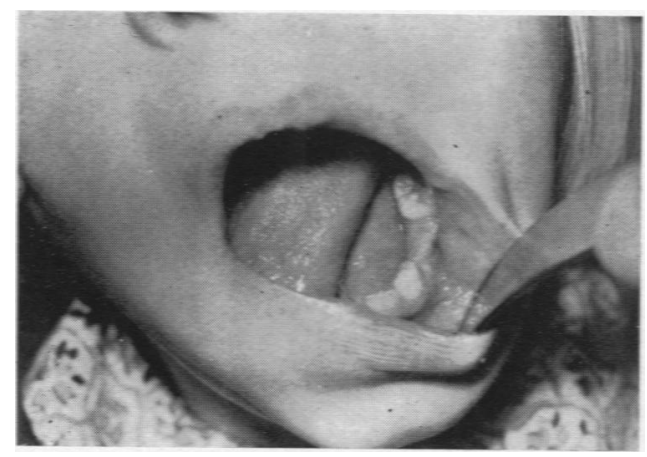

FKG. 9.-Case 6. Site of primary infection without scar formation or trace of previous uker three months later and approximately five months after infection. was complete without scarring. Thus, by the time the meningitis was cured, the site of the primary infection had disappeared (Fig. 9) leaving no trace other than the scar of the gland abscess in the neck. Within six months, a gland adjacent to the original abscess enlarged and was removed together with the scar of the first lesion. She is still well, two years later, and calcification is now visible at the site of the gland.

This child undoubtedly had an alveolar abscess and acute submandibular adenitis. Tooth extraction was followed by primary infection in the tooth socket and sulcus, and tuberculous meningitis subsided within eight weeks. It is the only case in which we have seen satellite nodules in a primary lesion on a mucosal surface.

Case 7. A boy aged 8, the elder of two children, was admitted to hospital on December 19, 1953, with a softening gland abscess well forward in the right submandibular region. He had been ill since the morning of October 29, when he awoke to find the right side of his face tender and swollen, and a small tender gland under the ramus of the mandible, on the same side. This swelling became bigger and the gland remained tender for $\mathbf{4 8}$ hours. Two days later he was aware of a purulent discharge in his mouth, and afterwards the swelling of the face rapidly disappeared but the gland remained enlarged until his dentist referred him to hospital where he had a tooth removed. But the alveolar abscess

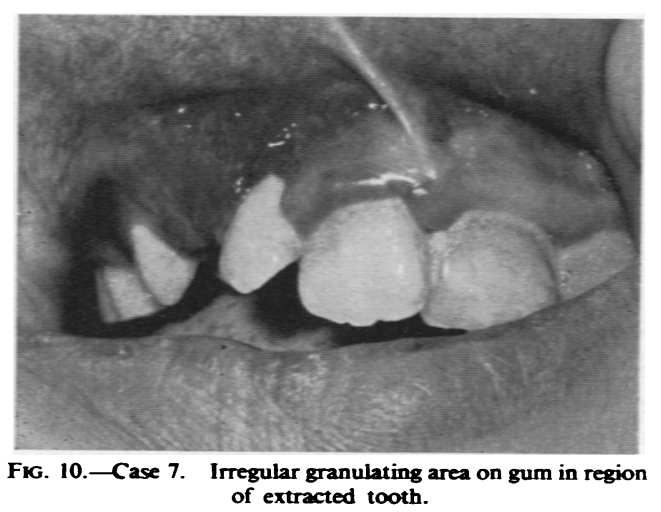

continued to discharge and the tooth crater did not heal satisfactorily. A fortnight later a biopsy revealed tuberculous granulation tissue in the tooth socket. Slowly the submandibular gland enlarged, and, when first seen in the Children's Department on December 15, was soft with early reddening of the skin. In the mouth over the gum of the right upper canine was an irregular granulating area (Fig. 10), in the centre of which a bead of green pus exuded through a sinus. He was not in good general health, but no other lesions were present and there was no other evidence of tuberculosis. On December 24 the gland swelling was incised; the pus contained tubercle bacilli and the wall of the gland abscess showed caseating tuberculosis. He was given streptomycin (1 g. daily) and isoniazid (I.N.H.) (250 mg. daily). There was an almost immediate improvement in his general health, the gland 
incision healed, and the granulating area on the gum diminished. This therapy was continued for a month, and I.N.H. for one month more. At the end of this time a small granulating area still showed on the gum, but the scar in the gland had firmly healed. When seen in August, 1954, there was a small sequestrum in the bone; this was removed, and later an ectopic canine tooth erupted.

\section{Discussion}

These seven cases all present the combination of a painless tuberculous ulcer in the mouth and a regional tuberculous lymphadenitis. No evidence of other primary infection or earlier tuberculous lesion was present in any patient. The only proof of primary infection lacking is knowledge of the tuberculin state of the patient before the appearance of the complex. But we have already made the point that this knowledge would be very exceptional in clinical work.

In no case could we establish contact with an infectious adult, but in the only case where the organisms were typed they were human in origin (Case 4).

The seven cases fell into two groups: five with a history of trauma and two without it. In four of the first group the trauma was that of dental extraction, and three of these children had also alveolar abscesses and a preceding acute lymphadenitis; the other (Case 2) followed the extraction of carious teeth without acute abscess formation. The primary lesions following dental extractions were at the site of the tooth socket or in the sulcus between the gum and the cheek, ranging in shape and size from a circular lesion in Case 2 to a long, irregular ulcer in Case 6 and Case 3. In one case at least (Case 5) the lesion was so small and apparently insignificant that there was doubt if a biopsy would be worth while, and we could not obtain a satisfactory photograph. In one (Case 7) the presence of tuberculous granulation tissue was masked by the discharging alveolar sinus. These lesions have quite disappeared as they healed or as permanent teeth have erupted, and their presence could not have been suspected later.

The two cases without history of injury were different from those just described, but strikingly similar to each other (Cases 1 and 4), with a large painless ulcer on the gum above normal intact teeth. In each case the gland swelling brought the patient to the family doctor, although both girls knew the lesions were present in the mouth. These lesions healed satisfactorily, but have left an outline of their margins on the alveolar mucous membrane which must correspond to the scar seen in cases of skin tubercle where there is no history of trauma (Miller, 1953).

Thus, it seems that any chronic lesion in the mouth, any area of dental trauma which fails to heal completely, or any area of granulation tissue, is under suspicion and should be examined histologically. If there is also swelling of the glands, the possibility of primary tuberculosis should certainly be considered, and we think that a more adequate search whenever submandibular glands have been recently involved would reveal more cases of primary foci in the mouth. But the primary focus must sometimes be very small and inconspicuous, for we have seen several cases within the period of this study when the glands were recent and no other evidence of tuberculosis existed, and yet, despite the most careful search, we could find no trace of a primary focus in the mouth.

The glands in this group of cases were all in the submandibular area except in Case 1 where the facial was the gland first involved and then the tonsillar. In five cases the glands were hard and discrete when first seen. Two were removed before softening (Cases 4 and 5), and these have not given rise to further trouble. In the other five cases the glands softened before surgical treatment was undertaken. In four of these, incision was the only treatment possible, and in all four further abscesses formed in neighbouring glands. In only one case has there been any evidence of haematogenous lesion in the form of meningitis appearing within eight weeks of infection. Cases 1-5 have evidence of calcification at the regional glands, but no other calcification in the neck, chest, or abdomen; Cases 6 and 7 have not yet developed radiological calcification in the regional glands but may yet do so.

\section{Summary}

The histories of seven patients aged from 2 to 17 years are given, and the reasons are advanced for considering that they are suffering from primary tuberculous infection in the mouth. The characteristics of the primary lesions are described, and the point is made that they may disappear leaving no scar. If so, the origin of the glands cannot be determined afterwards. There is some evidence that glands should be removed when firm, for if they spontaneously soften, subsequent secondary abscesses are common.

We wish to record our thanks to our colleagues in the Departments of Bacteriology, Pathology, Radiology, and Surgery in the Royal Victoria Infirmary, and to the Director of the Department of Medical Photography of King's College.

Boyes, J. (1950). Proc. roy. Soc. Med., 43, 503.

Brand, T. A and Ballard, C. F. (1951). Archives of Disease in Childhood, 26, 261.

Cameron, C. (1939). Brit. J. Tuberc., 33, 157.

Duken, J. (1933). Z. Kinderheilk., 55, 687.

Galloway, J. W. and Horne, N. W. (1953). Brit. dent. J., 95, 9.

Milker, F. J. W. (1953). Lancet, 1, 5. 